\title{
PRINCÍPIO DA SUSTENTABILIDADE: LICITAÇÕES E A REDEFINIÇÃO DA PROPOSTA MAIS VANTAJOSA
}

\author{
PRINCIPLE OF SUSTAINABILITY: THE RE-BID PROPOSAL AND MORE \\ ADVANTAGEOUS
}

\author{
Juarez Freitas ${ }^{1}$
}

\begin{abstract}
RESUMO - Este artigo visa a sustentabilidade das cidades, o que de fato é constitucional e dentre outros temas aborda a questão de resíduos sólidos soltos no ar (emissões de poluentes ou cancerígenos), demonstrando mediante políticas e administração pública que é possível ter o que é de fato, direito de todos, apresentando licitações para que ocorram melhores modificações.
\end{abstract}

PALAVRAS-CHAVE - Sustentabilidade. Licitações. Administração. Políticas públicas.

ABSTRACT - This paper aims at the sustainability of cities, which in fact is constitutional and among other issues addresses the issue of solid waste released into the air (emissions of pollutants and carcinogens), demonstrating through policies and public administration that it is possible to have what is in effect, right of all, with prcurement for best modifications to occur.

KEYWORDS - Sustainability. Procurement. Administration. Public policy.

\section{CONSIDERAÇÕES INICIAIS}

As licitações precisam incorporar, ao escrutínio das propostas, os incontornáveis critérios paramétricos de sustentabilidade para ponderar os custos (diretos e indiretos) e os benefícios sociais, ambientais e econômicos. Não se trata de simples faculdade, tampouco de modismo passageiro, como costuma objetar o conservadorismo redutor. Tampouco matéria de discricionariedade, que restasse isenta de controle quanto à licitude em sentido amplo. Trata-se de assumir, vez por todas, que, em qualquer processo licitatório, o Estado tem de implementar políticas públicas, com o desempenho da função indutora de práticas sustentáveis, ao lado da função isonômica de oferecer igualação formal e substancial de oportunidades.

\footnotetext{
${ }^{1}$ Presidente do Instituto Brasileiro de Altos Estudos de Direito Público, Prof. Titular do Mestrado e Doutorado em Direito da PUCRS, Prof. de Direito Administrativo da UFRGS, Pós-Doutorado em Direito na Universidade Estatal de Milão, Visiting Scholar nas Universidades de Oxford e Columbia. Membro do Conselho Nato do Instituto Brasileiro de Direito Administrativo, Presidente do Instituto de Direito Administrativo do Rio Grande do Sul, Advogado, Consultor e Parecerista. E-mail: juarezfreitas@uol.com.br.
} 
Vale dizer, as licitações e as contratações públicas obrigatoriamente terão de ser praticadas e controladas num horizonte intertemporal dilatado e mais consequente. E não só: impõe-se adicionalmente que todos os atos $e$ contratos administrativos passem a ser sindicados à base do mandamento da sustentabilidade, que não é simples declaração programática. É diretriz vinculante, orientada para procedimentos e resultados, de cuja força normativa se podem extrair as regras aptas a depurar as cores, ora cinzentas, da gestão pública. Mais do que "verde", quer-se uma licitação com todas as cores limpas.

As gerações futuras são, desde já, titulares de direitos fundamentais, de modo que o longo prazo, acompanhado do controle preventivo, torna-se variável obrigatória no julgamento das propostas administrativas. Nessa perspectiva, eis as ideias de fundo, a serem formuladas na presente exposição:

(a) a sustentabilidade, no sistema brasileiro, é princípio de envergadura constitucional, não somente aplicável na seara do Direito Ambiental, mas também no Direito Administrativo, entre outras províncias do sistema;

(b) as licitações, com a observância justificada dos critérios de sustentabilidade, encontram-se forçadas a conferir, desde a tomada de decisão, prioridade fática e jurídica máxima às políticas públicas que ensejam o bem-estar das gerações presentes, sem impedir que as gerações futuras produzam o seu próprio bem-estar;

(c) as licitações sustentáveis trabalham com modelos paramétricos de estimativas razoáveis dos custos, diretos e indiretos, sociais, ambientais e econômicos, na ciência de que o melhor preço é aquele que implica os menores impactos e externalidades negativas e, concomitantemente, os maiores benefícios globais.

\section{SUSTENTABILIDADE E LICITAÇÕES PÚBLICAS}

\subsection{Princípio constitucional da sustentabilidade ou do desenvolvimento sustentável é norma de aplicabilidade direta e obrigatória nas licitações e contratações públicas brasileiras}


A Constituição brasileira, no seu preâmbulo, consagra 0 desenvolvimento como "valor supremo", ladeado pelo bem-estar, pela igualdade e pela justiça. Mas qual desenvolvimento? A leitura sistemática da Carta indica que só pode ser o desenvolvimento sustentável, sobretudo em função dos arts. 3o, 170, VI, e 225, da CF. Com efeito, o desenvolvimento, constitucionalmente pretendido, é multidimensional (social, ambiental, econômico, ético e jurídico-político) e sistêmico. Tais dimensões precisam ser promovidas integradamente. Em outras palavras, bem observadas as coisas, 0 sistema normativo prescreve o desenvolvimento intra e intergeracional, promotor do ambiente limpo e da equidade social, na ciência de que ambientes iníquos afetam a sociedade inteira, em especial no atinente à saúde.

Como demonstram Wilkinson e Pickett (2009), "iniquidade causa danos à sociedade inteira. Comparam pessoas de mesma renda, educação ou classe, entre vários países, e constatam, não por acaso, que apresentam melhor saúde (inclusive mental) aquelas que vivem em sociedade menos desiguais."

Quer dizer, o constituinte pretende fomentar o desenvolvimento integrado, o qual, sem preconizar uma postura passiva perante a natureza, determina razoabilidade à atuação humana que precisa gerar, com limites e cautelas, a prosperidade contínua, não o simplório e utilitarista crescimento econômico, medido no não menos simplório Produto Interno Bruto. Para ilustrar o raciocínio: a poluição do ar pode ser o subproduto do crescimento econômico de curto prazo, mas se, em determinaas condições, implicar custos ambientais e sociais desmesurados, colide com 0 imperativo do desenvolvimento sustentável e será reprovável. Há, sem maiores controvérsias, atividades econômicas venenosas que provocam mais danos do que valor agregado.

Muller, Mendelsohn e Nordhaus (2011, p. 101-105) discorrem sobre o custo social da poluição do ar, em termos de saúde e produtividade, apontando aquelas indústrias ("solid waste combustion, sewage treatment, stone quarrying, marinas, and oil and coal-fired power plants"), nas quais os danos ambientais são superiores ao valor agregado. Ademais, propõem, com pertinência, a inclusão das externalidades ambientais no "system of national 
accounts." Não são tais atividades, por certo, que o Estado Constitucional colima fomentar.

Nesse diapasão, a Carta estabelece o desenvolvimento sustentável como "valor supremo" e, a partir do art. 225, fácil inferir que se trata de princípio constitucional, imediatamente vinculante, o qual obriga em todos os campos do sistema jurídico. Para Freitas (2012), este enfoque tem o condão de modificar o próprio modo de conceber e interpretar o sistema jurídico em todas as suas áreas.

Gera regras derivadas, desse modo, até sem carência de "interpositio legislatoris", à esfera dos atos, procedimentos e contratos administrativos, que precisam contribuir para a qualidade de vida das gerações presentes, sem a supressão do bem-estar das gerações futuras.

Portanto, além de "valor supremo", o desenvolvimento sustentável é um mandamento constitucional, conforme referido pelo próprio Supremo Tribunal Federal, quando do julgamento da ADIn 3.540 MC/DF:

O princípio do desenvolvimento sustentável, além de impregnado de caráter eminentemente constitucional, encontra suporte legitimador em compromissos internacionais assumidos pelo Estado brasileiro e representa fator de obtenção do justo equilíbrio entre as exigências da economia e as da ecologia [...].

Dito de outra maneira, sem admitir retrocesso hermenêutico, o EstadoAdministração tem o dever de aplicar a Lei Fundamental de ofício, construindo e reconstruindo as regras instrumentalmente voltadas a vivificar o princípio constitucional da sustentabilidade, entendido em consórcio indissolúvel com os demais princípios. Trata-se - convém reiterar - de diretriz vinculante e de pronta concretização administrativa, jurisprudencial e legislativa, que se encontra entrelaçado a outros princípios, como prevenção e precaução, e que guarda sinergia, por exemplo, com o princípio do poluidor-pagador. Vide, a propósito, CF, art. 225, $3^{\circ}$ e Lei $6.938 / 81$, art. $4^{\circ}$, VII.

Mais: toda discricionariedade administrativa encontra-se plenamente vinculada à sustentabilidade: não se depende de regras legais por acréscimo (ainda que esclarecedoras normas legislativas tenham surgido recentemente, como será enfatizado) para cobrar a aplicação imediata do princípio constitucional. 
Justamente do caráter vinculante, surge o lastro que ampara, por exemplo, o ato administrativo que fixa limites razoáveis para emissões de poluentes ou que limita o cancerígeno benzeno em líquidos.

A propósito, o MPF em Minas Gerais firmou, em 2011, termo de ajustamento de conduta com três grandes fabricantes de refrigerantes, segundo o qual as empresas assumiram o compromisso de, no prazo de até cinco anos, tomar as providências para que todos os seus refrigentes de baixas calorias ou dietéticos cítricos observem, como máximo, a quantidade de 5 partes por bilhão ou 5 microgramas por litro de benzeno, limite estabelecido pela Anvisa para a água potável.

Não se trata de o administrador empreender inovação legislativa, nem de cometer usurpação de competência, senão de cumprir o dever de, no âmbito das atribuições regulatórias ou fiscalizatórias, imprimir a eficácia máxima possível à Constituição, no cerne.

Nessa chave, nas licitações e contratações administrativas, força assumir que a proposta mais vantajosa será sempre aquela que, entre outros aspectos a serem contemplados, apresentar-se a mais apta a causar, direta ou indiretamente, o menor impacto negativo e, simultaneamente, os maiores benefícios econômicos, sociais e ambientais. Por esse prisma, o sistema de avaliação de custos, sob pena de violação flagrante ao princípio constitucional em apreço, terá de ser reformulado e incluir os custos indiretos, no intuito de estimar os dispêndios futuros a serem efetuados em função dos previsíveis impactos sistêmicos das decisões administrativas tomadas e dos riscos assumidos. Ou seja, antes de licitar, não se podem ignorar, candidamente, os custos ambientais, sociais e econômicos de cada escolha administrativa.

Cumpre, nessa perspectiva, ao Estado-Administração influenciar a matriz produtiva, num foco de convergência para que os fornecedores comecem a se tornar vigilantes quanto à sustentabilidade do ciclo de vida dos produtos, conforme dispõe a Lei 12.305/2010, em seu art. 3ํ, IV, - desde a obtenção de matérias-primas e insumos, passando pelo processo produtivo e consumo até a disposição final. Por exemplo, imprescindível assumir, nos contratos administrativos, a responsabilidade compartilhada pela destinação final dos resíduos e, quando couber, pela logística reversa. Novamente, não se 
trata de matéria de maior ou menor predileção do administrador, mas de incontornável obrigação legal e constitucional, ainda profundamente negligenciada pelos administradores e, não raro, pelos controladores.

Sempre para ilustrar: o reuso de água e a adoção de medidas de poupança de energia não são simples escolhas, escravas de supostos juízos de conveniência e de oportunidade. Não. Apresentam-se, na realidade, como resultantes deontológicas do princípio constitucional da sustentabilidade e das regras que, expressamente ou por inferência, auxiliam a densificá-lo. No limite, a obra errada e inútil, o serviço nefasto e o produto nocivo compõem o quadro das inadmissíveis violações fáticas e jurídicas ao princípio.

Ademais, importa ter presente, em nome da judiciosa e renovada calculabilidade, que, não raro, o custo para investir, por exemplo, no monitoramento do uso de recursos hídricos ou da energia costuma significar investimento de " $\mathrm{x}$ ", contudo propiciar, ao longo de alguns anos, uma economia da ordem de várias vezes " $x . "$

Também os financiamentos públicos, mercê do princípio em tela, encontram-se compelidos, normativamente, a inserir considerações precisas de viabilidade no longo prazo, de ordem a considerar, transparentemente, os custos diretos e indiretos, bem como os riscos associados às externalidades negativas. Não somente: o financiamento tem de contemplar a sustentabilidade, em todas as suas facetas, inclusive para evitar o ingresso em empreendimentos temerários e para manter distante a "tragédia grega" da insolvência ou da execução falha.

$\mathrm{Na}$ esfera licitatória, portanto, mister imediatamente induzir (um dos papeis fulcrais do edital sustentável), a redução dramática do uso de produtos ambientalmente nocivos e tóxicos, com o incentivo de técnicas e propostas alternativas. Por exemplo, as merendas escolares devem ser compostas exclusivamente de alimentos isentos de agrotóxicos (seriamente certificados), com mais antioxidantes e sem cancerígenos, a exemplo da experiência exitosa de Itaipu, no Programa Cultivando Água Boa, em parceria com os Municípios lindeiros ao lago, com avanços nos projetos de educação ambiental e agricultura orgânica e com repercussão expressiva na merenda escolar sem veneno. 
Por sua vez, os edifícios públicos devem ser construídos de maneira sustentável, não apenas com a adoção de pontuais tecnologias "verdes"de fachada, mas convertidos em microusinas de energias renováveis. Mais: uma construção em área contaminada simplesmente não pode ser tolerada (às vezes, com a cúmplice e censurável leniência dos controles), sem que se proceda a completa descontaminação prévia. Outra aplicação: os projetos básicos e executivos, para a contratação de obras e serviços de engenharia, devem contemplar opções que reduzam os custos de manutenção e de operacionalização, não apenas os de construção. Eis a concretização da sustentabilidade.

Ainda: os veículos a serem adquiridos pelo Poder Público haverão de ser os menos poluentes, não emitindo emissão de níveis nocivos de enxofre e de outros venenos. A preferência deve recair sobre veículos elétricos, híbridos ou movidos a biocombustível, que adotem rigorosos controles de emissão, no intuito de enfrentar a poluição do ar, nos grandes centros urbanos, fenômeno que, frequentes vezes, assume proporções humanamente fatais (comprovadamente, milhares de mortes acontecem, a cada ano, com nexo causal diretamente formado, a partir da contaminação do ar).

Adicional observação, no rol das ilustrações: apresenta-se inescapável a implementação, também por intermédio dos certames licitatórios, daquelas políticas públicas que valorizam a mobilidade urbana, com incentivo deliberado e prioritário ao transporte público de qualidade, a par do incremento de outros modais de transportes (ferrovias e hidrovias) para o escoamento de pessoas e produção, vide o Comunicado do IPEA 113, Poluição Veicular Atmosférica, setembro de 2011, p. 24, que aposta em alternativas tecnológicas limpas e, em lugar de políticas contraditórias que favorecem o transporte individual, postula a prioridade do transporte coletivo, haja vista a saturação crítica do modal rodoviário, conforme demonstram Basserman, Veiga e Abranches ( 2009, p. 320)

Como se afigura incontendível, o trânsito, nas metrópoles, é robusto e estressante testemunho da falta crônica de planejamento sistêmico, que se revela, a cada dia, mais e mais insustentável, uma vez que as cidades fazem esforço meritório para vencer gargalos, como Copenhague e Oslo. Em toda 
parte, exige-se acentuada mudança de concepção e de planejamento dos centros urbanos, muitos dos quais verdadeiramente impróprios para a vida digna.

Enfim, tais exemplos são suficientes para realçar o papel que o EstadoAdministração deve exercer no atinente à implementação inadiável de licitações e contratações públicas, em consonância com o princípio positivo da sustentabilidade multidimensional, cuja reciprocidade causal foi demonstrada pela pesquisa da FVG, intitulada "Benefícios econômicos da expansão do saneamento ambiental", de julho de 2010.

Portanto, numa primeira conclusão, consigne-se que não se trata de simples faculdade, mas de obrigação constitucional e legal realizar as licitações e contratações administrativas sustentáveis, em todos os Poderes e por todos os Poderes.

Dito de outro modo, o dever de efetuar contratações públicas sustentáveis implica promover a reconformação da arquitetura das instituições e dos comportamentos: guiado pelo imperativo fundamental da sustentabilidade, o gestor precisa, em todas as relações de administração, promover o bem-estar das gerações presentes, sem inviabilizar o bem-estar das gerações futuras, cujos direitos fundamentais são, desde logo, plenamente reconhecidos pelo ordenamento jurídico

Trata-se de variação do conceito, centrado em necessidades, contido no Relatório Brundtland (1987), em que pese o grande avanço que representou. $O$ conceito de sustentabilidade, aqui defendido, é o de princípio constitucional que determina, independentemente de regulamentação legal, com eficácia direta e imediata, a responsabilidade do Estado e da sociedade para a concretização solidária do desenvolvimento material e imaterial, socialmente inclusivo, durável e equânime, ambientalmente limpo, inovador, ético e eficiente, no intuito de assegurar, no presente e no futuro, o direito ao bem-estar, conforme a minha proposta in Sustentabilidade: Direito ao Futuro, ob.cit..

\subsection{Nas licitações e contratações, o Estado-Administração tem de ser suficiente e eficaz na proteção ativa dos direitos fundamentais das gerações presentes e futuras}


Assentado esse ponto, cumpre notar que o controle mais significativo dos atos, procedimentos e contratos administrativos passa a ser o da eficácia (CF, art.74), em lugar da simples eficiência ou da mera legalidade (CF, art.37). Com efeito, a eficiência, em situações paradoxais, pode até produzir mais velozmente o insustentável. Logo, a densificação do princípio da eficácia (entendido como obtenção de resultados e processos compatíveis com os objetivos fundamentais da Carta, não apenas aptidão de produzir efeitos no mundo jurídico) é o que mais importa para o desenvolvimento sustentável. O Estado-Administração não pode prosseguir insuficiente, omisso e ineficaz na proteção dos direitos fundamentais das gerações presentes e futuras, como exposto por Dietlein (2005).

Nesse enfoque, podem-se catalogar determinadas regras densificadoras do princípio do desenvolvimento sustentável em três grandes grupos: (i) regras legais; (ii) regras administrativas expressas ou decorrentes do poder regulamentar e (iii) regras interpretativas inferíveis do sistema constitucional, que servem para colmatar lacunas eficaciais e suprir a tópica insuficiência na proteção dos direitos fundamentais. Convém grifar: revela-se despropositada e temerária qualquer espera excessiva por adicionais regras expressas, uma vez que a demora pode ser - e tem sido - corrosiva da eficácia do princípio constitucional em tela. Enfatize-se, pois, a vinculatividade direta do sistema, a qual não pode ser ofuscada ou obliterada pela morosidade ou pela inércia administrativa inconstitucional.

Quer dizer, o Estado-Administração não pode dar de ombros para os deveres adaptativos requeridos pelo desenvolvimento sustentável, sob a alegação pusilânime de carência de regras expressas. As regras jurídicas podem perfeitamente ser inferidas à base do dever de imprimir eficácia crescente ao sistema normativo e destinadas a propiciar a catalização eficacial dos princípios, objetivos e direitos fundamentais, conforme demonstra Freitas (2010, p. 228-271).

Dito isso, convém destacar que, no grupo das regras expressas, no sistema brasileiro, (i), figura a Lei de Mudanças Climáticas (Lei 12.187, de 2009). Tal diploma estipula a adoção de providências que estimulem, com 
celeridade, o desenvolvimento de processos e tecnologias, aptos a contribuir para a economia de baixo carbono, assim como para a adaptação, com o estabelecimento de critérios seguros de preferência, nas licitações públicas, para aquelas propostas que propiciem maior economia de energia, água e outros recursos naturais (art. 6으. XII). Note-se que tais critérios de preferência devem ser aplicados até para a simples autorização e, "a fortiori", para a celebração dos contratos públicos, que requerem estabilidade e pressupõem alta previsibilidade das condutas.

Outra regra densificadora digna de menção está alojada no corpo da Lei de Licitações, alterada pela Lei 12.349, de 2010, estabelecendo que a licitação "destina-se a garantir a observância do princípio constitucional da isonomia, a seleção da proposta mais vantajosa para a administração e a promoção do desenvolvimento nacional sustentável." Isonomia e sustentabilidade social, econômica e ambiental são, numa equação responsável a longo prazo, princípios compatibilizáveis e de aplicação obrigatória conjunta.

Como acentua Junior (2011, p. 71 ), "em verdade, a Lei 12.349/10 veio dar cobro à omissão do regime legal geral das licitações e contratações (...) que não explicitava (...) o que já decorria da Constituição da República e vinha sendo alvo de regras em leis setoriais e normas infralegais específicas."

Curiosamente, a experimental Lei do Regime Diferenciado de Contratações (Lei 12.462, de 2011), teve o cuidado de repetir, no seu art. 3º, que as licitações e contratações realizadas em conformidade com o princípio do desenvolvimento sustentável e, no art. $4^{\circ}$, fez constar inovadoramente que, nas licitações e contratos, terá de ser observada, entre outras, a diretriz de "busca da maior vantagem para a administração pública, considerando custos e benefícios, diretos e indiretos, de natureza econômica, social ou ambiental, inclusive os relativos à manutenção, ao desfazimento de bens e resíduos, ao índice de depreciação econômica e a outros fatores de igual relevância." Trata-se, pois, de exigir a avaliação inédita, pelos controles interno e externo, dos custos, diretos e indiretos.

Certamente, a referência abrangente a custos econômicos, sociais e ambientais é oportuna tradução, em seu amplo espectro, do princípio 
constitucional da sustentabilidade, ainda que veiculada em diploma a ser aperfeiçoado. Mas não só: no art. 10, admite-se, com a pertinente motivação, na contratação das obras e serviços, a remuneração variável vinculada ao desempenho da contratada, com base em metas e critérios de sustentabilidade, estipulados no instrumento convocatório e no contrato. $\mathrm{E}$ mais: dispõe o art. 19 que, sem miopia, o julgamento pelo menor preço ou menor desconto terá de considerar o menor dispêndio da administração, porém atendidos os parâmetros de qualidade, convindo sublinhar que os custos indiretos haverão de ser necessariamente contemplados na definição do menor dispêndio.

Entretanto, a consagração da sustentabilidade, no plano das regras legais, não cessa por aí.

Entre os objetivos da Política Nacional de Resíduos Sólidos (Lei 12.305, de 2010, art.7ํ. XI), consta a prioridade obrigatória, nas aquisições e contratações governamentais, para produtos reciclados e recicláveis e bens, serviços e obras que considerem os critérios compatíveis com padrões de consumo social e ambientalmente sustentáveis. Desse modo, sempre que possível optar entre um ou outro bem, a escolha legítima só pode recair sobre aquele que estiver em sintonia com as exigências globais da sustentabilidade. Não se admite, pois, esposar retoricamente o sentido fraco da prioridade estipulada, dado que se impõe descartar os produtos que não apresentarem as citadas características, sobremodo perante alternativas com preços razoáveis e condições técnicas abalizadas para atender os requisitos da sustentabilidade. O que se objetiva, nesse diploma, é acelerar a transição para os negócios "verdes" e, com isso, para novos padrões de consumo, na certeza de que os métodos usuais ("business as usual") simplesmente tendem a tornar a vida humana inviável.

O segundo grupo apontado (ii) é o das regras administrativas expressas, as quais, a seu modo, também visam a concretizar o princípio constitucional da sustentabilidade, no exercício do poder regulamentar. A título ilustrativo, cumpre citar a Instrução Normativa 1/2010, da Secretaria de Logística, do Ministério do Planejamento, que dispõe sobre os critérios obrigatórios de sustentabilidade, na aquisição de bens, contratação de serviços ou obras pela 
Administração Pública Federal direta, autárquica e fundacional. Com acerto, esclarece o ato administrativo que tais critérios, no atinente às especificações, devem constar no instrumento convocatório, "considerando os processos de extração ou fabricação, utilização e descarte dos produtos e matérias primas" (art.1ํ). Ao lado disso, remete, judiciosamente, ao art. 12 da Lei o 8.666, e desdobra a regra legal, orientando-a no sentido de que as especificações e demais exigências do projeto básico ou executivo, para contratação de obras e serviços de engenharia, devem ser elaboradas visando à economia da manutenção e operacionalização da edificação, além da utilização de tecnologias que reduzam o impacto ambiental.

Como se constata, o ato administrativo em apreço detalha, de forma organizada, relevantes mandamentos presentes no sistema. Por sinal, no caso de bens e serviços, o art. 50 deixa estampado que as Administrações poderão exigir que os bens sejam constituídos, no todo ou em parte, por material reciclado, atóxico, biodegradável ou que sejam observados os requisitos ambientais para a obtenção de certificação do Inmetro como produtos sustentáveis ou de menor impacto ambiental em relação a similares. A despeito da literalidade, não se trata de mera faculdade, mas de obrigação constitucional, dado que o princípio da sustentabilidade impõe prevenção e precaução, conforme referido por Machado (2010). Nessa linha, em acréscimo, prescreve corretamente que, antes de iniciar o processo de aquisição, a Administração Pública precisa verificar a disponibilidade e a vantagem de reutilização de bens, por meio de consulta ao fórum eletrônico de materiais ociosos.

Dito de modo sintético, tal ato administrativo, ainda que mereça ser aperfeiçoado, revela-se, para já, vetor útil de aplicação do mandamento constitucional da sustentabilidade, que determina condutas estatais voltadas ao desenvolvimento ambientalmente limpo, eficiente e ético, socialmente equânime, de modo a assegurar, no presente e no futuro, as condições efetivas para o bem-estar.

Regras similares existem ou devem existir, no âmbito dos Estados, Municípios e Distrito Federal, sendo lícito asseverar que regras federativas já 
se encontram perfeitamente acessíveis para que as contratações públicas passem, de pronto, a ser sustentáveis, em todos os Poderes e esferas.

Nesse diapasão, salienta-se que $O$ art. $3^{\circ}$, da Lei de Licitações, ao consagrar o princípio do desenvolvimento sustentável, veicula, como parece incontroverso, norma geral, logo aplicável a todas as esferas federativas.

Contudo, caso se constate remanescente omissão de regra legal ou administrativa expressa, resta o caminho inteiramente plausível de extrair 0 intérprete-administrador ou o controlador, por força de inferência, as regras do terceiro grupo (iii), isto é, aquelas construídas, por assim dizer, pelo aplicador que não se subtrai do compromisso de oferecer, motivadamente, a contribuição à eficácia do princípio da sustentabilidade. A não ser assim, a suposta falta de regras seria usada como arma contra a força vinculante do sistema constitucional, arma que nenhum agente público idôneo tem porte para carregar.

Em suma, conclui-se que existem regras suficientes (dos três grupos citados) para se considerar plena e imediatamente aplicável o princípio constitucional do desenvolvimento sustentável, nas licitações e contratações administrativas brasileiras.

\subsection{Licitações e Contratações: A proposta mais vantajosa é aquela que se encontra alinhada com políticas públicas sustentáveis}

Nada mais justifica que a licitação siga presa a critérios simplistas ou à metodologia tradicional e míope de julgamento e de controle. Melhor preço, frequentes vezes, é diferente do menor preço ou do preço míope, contemplado sob o prisma intertemporal. O certo é que os controladores, inclusive os Tribunais de Contas, deveriam assumir, na perspectiva abraçada, o protagonismo da redefinição da arquitetura licitatória, ao cobrarem, sem morosidade, o exame motivado dos custos e benefícios, diretos e indiretos, em termos econômicos, sociais e ambientais, de maneira parametricamente convincente.

Não é lícito negligenciar que a sustentabilidade representa - ao contrário do que dizem os seus críticos superficiais - um potencial ganho de eficiência, 
com redução significativa de custos, às vezes no plano imediato. Não por outro motivo, a sustentabilidade deixa de ser, gradativamente, um simples ardil para ganho de imagem ou de reputação, para se converter numa estratégia disseminada de agregação de valor para a Administração Pública e para as contratadas.

Afortunadamente, começa a se difundir a noção de que a sindicabilidade das decisões administrativas haverá de se estender no tempo e no espaço, para contemplar os múltiplos efeitos, numa permanente reavaliação, com reforço da programação, do planejamento e do monitoramento, no tocante aos impactos nos meios físico, biótico e socioeconômico.

É que os critérios estratégicos da sustentabilidade, no processo de tomada da decisão administrativa, requerem o maior distanciamento temporal e a capacidade de prospecção de longo prazo, com o abandono resoluto da visão reducionista dominante, segundo a qual o sistema jurídico cuidaria apenas do imediato e da obtenção do "preço míope".

Nessa ótica, o gestor público responsável não pode mais realizar juízos adstritos ao curto prazo, típico comportamento daqueles que não apenas desprezam os princípios constitucionais, como se alienam a interesses secundários. Como refere Freitas (2010), o gestor e o controlador devem vencer todo e qualquer traço de indolência acomodatícia que os impedem de fazer o melhor possível para todas as gerações: o horizonte haverá de ser o horizonte do Estado Sustentável, no qual o ciclo de vida dos produtos e serviços passa a ser escrutinado, preferencialmente de modo cautelar e antecipatório, oferecendo respostas aceitáveis, no teste da sustentabilidade, a ser descrito a seguir.

\subsection{Só as lentes da sustentabilidade permitem enxergar os novos critérios a serem observados, nas respectivas etapas do certame licitatório}

Avulta, nesse contexto de afirmação do princípio constitucional da sustentabilidade, uma tríade de questões centrais para a sua implementação exitosa nas licitações e contratações públicas. 
Uma primeira questão concerne aos antecedentes da licitação. Quer dizer, antes de o certame ser levado a efeito, impõe-se responder à indagação típica da sustentabilidade: é a licitação realmente necessária e apresenta benefícios que superem os custos diretos $e$ indiretos? Considerou 0 administrador público, com esmero e capacidade de cálculo - no sentido confiável do termo, referente à estima de custos diretos e indiretos, bem como benefícios ambientais, sociais e econômicos - a hipótese de resolver a demanda, com medidas de racionalização ou com o emprego daquilo que está disponível e ocioso? Mais: a decisão administrativa de licitar coaduna-se com o princípio da sustentabilidade em todas as suas dimensões, inclusive sociais e econômicas? Favorece a visão sistêmica ou contribui para formação de gargalos que só dificultam a vida de todos?

O dever de motivação, exercido nessa fase, terá de enfrentar, coerente e consistentemente, o mérito dessas questões conjuntas, na ciência de que o certame supérfluo ou lesivo - muito comum - não pode mais ser tolerado. Como se trata de questão que antecede a licitação, apropriado cogitar, desde o nascedouro, de licitações sustentáveis, e não apenas de contratações sustentáveis.

O certo, em homenagem ao art. 50 da Lei 9.784/99, é reconhecer o caráter cogente dessa motivação de maneira generalizada, em todas as licitações e contratações públicas e encapsular, na justificação do certame, o exame minucioso dos requisitos da sustentabilidade. Não se deve esquecer que, consoante o inciso I, do citado art. 50, da Lei 9.784, a motivação é obrigatória quando os atos administrativos "neguem, limitem ou afetem direitos e interesses". Ora bem, por conta das atuais circunstâncias, nada está mais exposto ao exame dos efeitos e do impacto sobre os direitos do que as decisões administrativas escrutináveis à luz do princípio constitucional da sustentabilidade. Numa frase: o que afeta o futuro, afeta o direito fundamental à sustentabilidade, logo deve ser devidamente justificado.

Prosseguindo no teste: uma segunda questão típica de desenvolvimento sustentável envolve a implementação propriamente dita do certame licitatório. Isto é, superada a primeira fase, é chegado o momento de definir o objeto e de inserir, no exame da habilitação e no rol dos critérios de avaliação da 
proposta mais vantajosa, os requisitos da sustentabilidade ambiental, econômica e social. Requisitos que, na etapa do julgamento das propostas, transcendem - sem excluir - o exame da mera legalidade.

Reitere-se: no projeto básico, quando se cogita de orçamento detalhado, cumpre que, doravante, constem estimativas razoáveis dos custos, diretos e indiretos, relacionados às externalidades negativas, de sorte que, por exemplo, não se considere exclusivamente o custo econômico imediato para a construção de um prédio, mas também o da manutenção e o da operação, à vista das soluções adotadas.

Finalmente, uma terceira questão própria do teste da sustentabilidade é aquela relativa à fase de celebração e execução do contrato administrativo, isto é, ao cumprimento das obrigações pactuadas. Nessa fase, que não pode ser separada logicamente das anteriores, conferir-se-á, fiscalizatoriamente, se a estimativa compreensiva dos custos diretos e indiretos, acolhida no texto do contrato, resultou bem sucedida na execução, consoante o sopesamento e a pesagem dos custos e benefícios, expostos à reavaliação permanente dos aspectos comensuráveis e incomensuráveis, sempre com proporcionalidade e respeito ao equilíbrio econômico-financeiro intangível.

Estas três questões, que compõem o teste da sustentabilidade, são indissociáveis para o olhar que não se deixa confinar pela vista curta. De fato, só as lentes da sustentabilidade permitem enxergar dinamicamente os elementos a serem enquadrados, nas respectivas etapas do certame licitatório. Não são, por certo, elementos triviais, mas cruciais.

Em síntese, no intuito de melhor retê-los, eis os tópicos que se afiguram os mais relevantes para o teste dinâmico da sustentabilidade, aplicável ás licitações e contratações administrativas:

(a) antes de começar a licitação, crucial responder se existe conveniência motivada para iniciar o certame, inclusive verificar se existem, disponíveis ou disponibilizáveis, bens, produtos ociosos ou alternativos. No ponto, as perguntas centrais são: a decisão administrativa de licitar é compatível com o princípio da sustentabilidade em todas as suas dimensões? A licitação pode auxiliar o cumprimento das variadas regras protetivas, gerais ou individuais, da sustentabilidade? A quais políticas públicas, de estatura 
constitucional, a licitação específica deve atender prioritariamente, a partir da definição do objeto?

(b) Na fase de implementação do certame e na etapa de celebração e fiscalização subsequente do contrato administrativo, destacam-se indagações a serem respondidas a contento: quais são as especificações do objeto que, sem realizar discriminação negativa, reclamam tratamento diferenciado, segundo o princípio constitucional da sustentabilidade? A contratação administrativa contemplará o ciclo de vida dos produtos ou restará adstrita à variável do preço, numa perspectiva imediatista? A contratação traz resultados defensáveis a longo prazo ou reduz as oportunidades de gerações futuras produzirem o seu próprio bem-estar?

(c) Finalmente, as obrigações pactuadas, segundo o edital sustentável, são cumpridas de fato?

Uma vez diligentemente enfrentadas essas questões fulcrais, reciprocamente implicadas, resulta que, na hipótese de a licitação ser considerada necessária, haverá, ato contínuo, de passar pelo filtro, segundo o qual a escolha da proposta mais vantajosa não pode ser guiada pelo critério excludente e vesgo do preço, uma vez que, em determinadas circunstâncias, o gasto maior no presente pode representar expressivo ganho adiante, com a induzida redução dos custos futuros. Nessa ótica, a licitação e a contratação precisam tomar parte maiúscula no bojo das políticas de desenvolvimento sustentável, com o intento de estimular a formação de negócios de cores limpas e empreendimentos sustentáveis "lato sensu", inclusive eticamente.

Os critérios de sustentabilidade passam a ser concebidos, nessa linha, como instrumentos redefinidores do estilo, do modo e do tempo da gestão pública, mediante o redesenho do bloco de sindicabilidade e dos elementos vinculados dos julgamentos administrativos. Não se admite, portanto, qualquer contratação que comprometa irresponsavelmente a qualidade de vida das gerações presentes e futuras.

Nesse contexto, o princípio constitucional da sustentabilidade proíbe, simultaneamente, a ineficiência e a ineficácia, nas licitações e contratações públicas (finalidade inibitória). Obriga a prevenção e a antecipação, com planejamento estratégico e antevisão dos resultados de obras, serviços e 
utilização dos bens (finalidade antecipatória e prospectiva). Permite induzir os comportamentos intertemporalmente responsáveis (finalidade indutora).

Em razão disso, novos métodos menos sistemicamente onerosos serão sempre preferíveis. Exemplo: o processo eletrônico será preferível, "prima facie", na comparação com os processos de consumo de papel, ainda que as licitações de informática tenham de considerar, adequadamente, a destinação dos equipamentos digitais, como determina a Lei de Resíduos Sólidos.

Merece ênfase que a licitação sustentável supõe tomada de decisão que leve em consideração os efeitos públicos e privados, diretos e indiretos, prospectivamente. Vale dizer, a decisão administrativa idônea tem de respeitar processos e resultados futuros. Dito de outro modo, a licitação, norteada pelo mandamento da sustentabilidade (com o cumprimento das regras instrumentais relacionadas), pode-deve servir como promotora de políticas voltadas à equidade de longo alcance, com apreço à saúde pública e à redução (ou internalização) de externalidades negativas, nada se licitando que não se submeta ao crivo ampliado da ponderação custo-benefício, reconstruído para ser um julgamento mais rico, confiável e complexo do que o rotineiro.

Elkington (2012, p. 110) lembra que "a sociedade depende da economia, e a economia depende do ecossistema global, cuja saúde representa o pilar derradeiro"

Pode parecer tarefa simples, mas não é. O maior inimigo mora nos desvios cognitivos e emotivos que turbam a qualidade das decisões, como já referiam Khaneman, Slovic e Tversky (1982). Entretanto, se o desafio se mostra complexo, daí não segue qualquer impossibilidade paralisante de construção do desenvolvimento que importa.

Quando empregados devidamente, os novos critérios de julgamento se metamorfoseiam e evoluem para operar como autênticos critérios de sustentabilidade: o exame da razoabilidade dos custos (diretos e indiretos) passa a incorporar, necessariamente, a projeção includente de previsíveis demandas, materiais e imateriais, das gerações presentes e futuras.

Assim, a licitação, em lugar dos conhecidos vícios, começará a ser produtivamente responsável por notáveis transformações políticas, jurídicas, sociais, econômicas, ambientais e éticas. Não por acaso, as licitações, 
contendo especificações sustentáveis do objeto, ajudam a ensejar observância da diretriz de garantia do "direito a cidades sustentáveis", isto é, livres dos males trazidos pelo jugo excessivo dos combustíveis fósseis, com edifícios saudáveis e eficientes, o controle de qualidade do ar, a pertinente destinação dos resíduos (logística reversa e responsabilidade compartilhada), a economia de água potável e, sobretudo, com o planejamento integrado que leve em conta as condições reais de vida, em vez do urbanismo caótico e insalubre, comandado pelo indiferente império das coisas.

Nesse sentido, observa-se art. $2^{\circ}$, I do Estatuto da Cidade (Lei 10.257, de 2001), que traz que a política urbana tem por objetivo ordenar o pleno desenvolvimento das funções sociais da cidade e da propriedade urbana, mediante as seguintes diretrizes gerais, dentre as quais está a garantia do direito a cidades sustentáveis, entendido como o direito à terra urbana, à moradia, ao saneamento ambiental, à infra-estrutura urbana, ao transporte e aos serviços públicos, ao trabalho e ao lazer, para as presentes e futuras gerações.

Em suma, mudanças de estilo e de valores podem ser fortemente favorecidas pelas opções administrativas, que se deixem impregnar pelo princípio da sustentabilidade. Na lição de Sachs (2004), para intensificar a boa resposta aos desafios do desenvolvimento includente, urge investir num sistema idôneo e confiável de avaliação dos custos, que migre para parâmetros sérios de avaliação dos custos indiretos, sociais, ambientais e econômicos, de maneira a permitir a governança eticamente responsável e prospectiva.

Ainda, Elkington (2012, p. 170), alerta para o fato de que

não será suficiente 'esverdear' os produtos que as pessoas compram ou mesmo as indústrias que fabricam tais produtos. A mudança necessária para estilos de vida mais sustentáveis somente pode ocorrer com a mudança apropriada dos nossos valores.

Deveras, as licitações e contratações sustentáveis demandam a observância cabal de critérios que incluam projeções inteligíveis dos custos de longo espectro dos produtos e serviços, de ordem a atentar para a avaliação do ciclo de vida dos bens, contemplado o impacto, efetivo ou potencial, em todos os momentos, do início até a destinação final. 


\section{CONSIDERAÇÕES FINAIS}

Tudo considerado, útil propor o conceito de licitações norteadas pelo princípio constitucional da sustentabilidade: são aquelas que, com isonomia e compromisso efetivo com o desenvolvimento sustentável, visam a seleção de proposta mais vantajosa para a Administração Pública, ponderados, com a máxima objetividade possível, os custos e benefícios (diretos e indiretos) sociais, econômicos e ambientais.

Ou, de forma mais completa, são os procedimentos administrativos por meio dos quais um órgão ou entidade da Administração Pública convoca interessados - no bojo de certame isonômico, probo e objetivo - com a finalidade de selecionar a melhor proposta, isto é, a mais sustentável, quando almeja efetuar ajuste relativo a obras e serviços, compras, alienações, locações, arrendamentos, concessões e permissões, exigindo na fase de habilitação as provas realmente indispensáveis para assegurar o cumprimento das obrigações pactuadas.

Reitere-se: a sustentabilidade é mandamento constitucional. Incide em todas as províncias do sistema jurídico, de maneira a tornar inadiável a sua exteriorização imediata, também na seara administrativa. Assim, as licitações e contratações públicas, com a observância cogente dos critérios de sustentabilidade, precisam encarnar, em larga medida, as políticas públicas que ensejam o bem-estar das gerações presentes, sem impedir que as gerações futuras produzam o próprio bem-estar.

Devem operar, para tanto, com modelos e estimativas seguras, inteligíveis e confiáveis dos custos e benefícios sociais, ambientais e econômicos, levando em conta a preferência simultânea por menores impactos negativos e maiores benefícios globais.

Em última instância, formal e materialmente, o princípio constitucional da sustentabilidade, é lente que mudará, por inteiro, o Direito Administrativo, implicando, entre outras consequências, o famigerado preço míope. A Administração Pública terá de assumir o irrenunciável papel histórico de, em vez de externalização, induzir a internalização dos custos e incentivar os benefícios sistêmicos para o florescimento humano, tingido por limpas cores 
naturais, em lugar dos corantes do falso progresso. Tudo isso requer ativismo lúcido, objetivo e imparcial: o ativismo vinculado à Constituição. Afinal, na seara das relações administrativas, o Estado Constitucional tem de passar a cumprir, de ofício, o dever estratégico de, antes de mais nada, salvaguardar o direito ao futuro.

\section{REFERÊNCIAS}

DIETLEIN, Johannes - Die Lehre Von den grundrechtichen Schultzpflichten. Berlim. Duncker und Humblot. 2005.

ELKINGTON ,John - Sustentabilidade. Canibais com garfo e faca. São Paulo. M. Books, 2012.

FREITAS, Juarez - A Interpretação Sistemática do Direito. São Paulo. 5aㅡ ed. Malheiros, 2010.

FREITAS, Juarez - Sustentabilidade: Direito ao Futuro. Belo Horizonte $2^{\underline{a}}$ ed. Fórum. 2012.

KAHNEMAN, Daniel; SLOVIC, Paul; TVERSKY, Amos - Judgment under Uncertainty: Heuristic and Biases. New York. Cambridge University Press. 1982

MACHADO, Paulo A. L. - Direito Ambiental Brasileiro. São Paulo, 18 ed. Malheiros, 2010.

MULLER, Nicholas; MANDELSOHN, Robert; NORDHAUS, William Environmental Accounting for Pollution in the United States Economy. American Economic Review. 2011.

Revista do Interesse Público, Belo Horizonte. Fórum, ano 13, maio-jun. 2011.

SACHS, Ignacy - Desenvolvimento includente, sustentável, sustentado. Rio de Janeiro, Editora Garamond, 2004.

WILKINSON, Richard; PICKETT, Kate - The Spirit Level: Why greater equality makes societies stronger. New York. Bloomsbury Press. 2009.

Recebido para publicação: 06/12/2012

Aceito para publicação: 19/12/2012 